\title{
FERRITE LINE TO DECREASE RISE TIME OF HIGH-VOLTAGE NANOSECOND PULSES
}

\author{
V. Korchuganov, Yu. Matveev ${ }^{\dagger}$, D. Shvedov
}

\begin{abstract}
Fast kickers fed by high-voltage thyrotron generators are used for extraction of charged particles in e+ecolliders and synchrotron light sources. Thyratron generators can provide a rise time not less than (30-40) nsec. It is not always enough, especially for accelerator rings of small circumference. This work describes a method to achieve short rise time pulses with the help of coaxial lines filled with ferrite rings with a nonrectangular hysteresis loop and locating between the thyratron generator and fast kicker. Pulses with a rise time of (2 - 3) nsec at a level of (0.1 - 0.9) from the amplitude were achieved at a $40 \mathrm{nsec}$ initial rise time of thyratron generator pulses. The length ferrite filled line is $800 \mathrm{~mm}$.
\end{abstract}

\section{INTRODUCTION}

Shortening of the electromagnetic wave rise time in ferrites was revealed for the first time long ago [1].

This phenomenon was explained by the appearance of shock electromagnetic waves. A theory was created for ferrites with rectangular hysteresis loop. Ferrites with non-rectangular hysteresis loop were estimated to be unserviceable for shortening of rise time of pulses, because they will be broken down before their saturation. The authors of the presented work have shown a possibility to use ferrites with non-rectangular hysteresis loop to sharpen pulse edges of thyratron generators. These ferrites are easy to get and inexpensive, since they are serially manufactured in wide range at many sites. Manufacture of ferrites with rectangular hysteresis loop was developed in the sixties for the needs of computer engineering. Now this industry does not need in ferrite. Rings were of small dimensions, which restricted electrical strength of lines. Authors of main publications

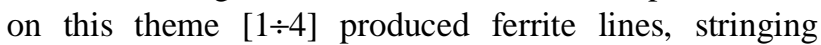
ferrite rings on a wire and placing such "garlands" in an armor of a coaxial cable, with subsequent submersion of them into a vessel with transformer oil. Amplitude of output pulses did not exceed $4 \mathrm{kV}$. Length of lines was (610) meters.

$\overline{\text { Y.G.Matveev@inp.nsk.su }}$

\section{DESIGNING OF HARD FERRITE- FILLED CO-AXIAL LINES}

Designs of Ferrite lines described in $[1 \div 4]$ are of little use in high-voltage nanosecond generators as concerns application of such generators in complicated complexes of charged particle storage accelerators, which require small-length ferrite lines of reliable, hard design.

Figure 1 presents a section of a co-axial ferrite line.

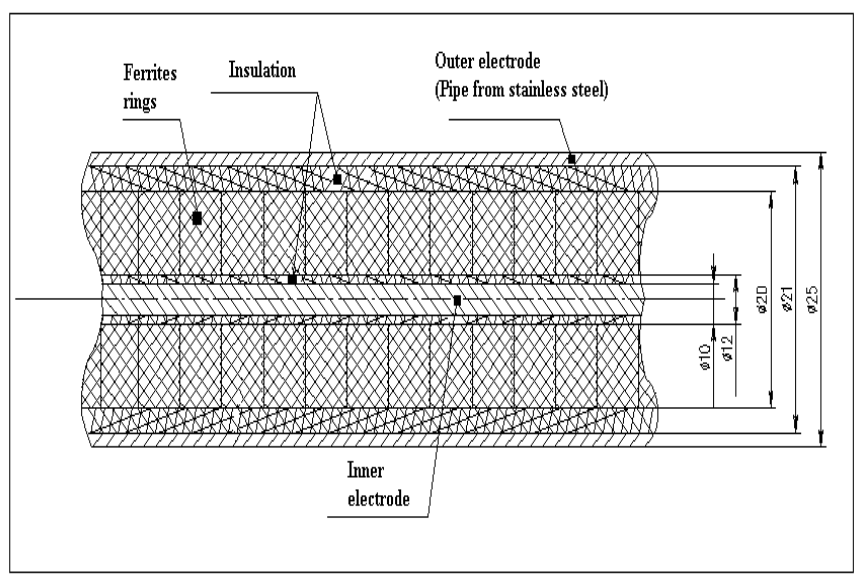

Figure 1. Section of the co-axial ferrite line.

A heat-shrinkage polyethylene tube is put on the inner conductor (a bar or a tube) of the ferrite line. 130 pieces $\mathrm{M} 20 \times 12 \times 6$ (trade-mark $1000 \mathrm{HH}$ ) ferrite rings are stringed on this polyethylene tube. From the outer side, the ferrites are covered by four layers of polyethylene film $0.1 \mathrm{~mm}$ thick. All that is placed in a tube of stainless steel and is sealed hermetically. In order to increase serviceability, the tube is filled with insulating gas $\left(\mathrm{SF}_{6}\right)$ under a pressure as high as $0.5 \mathrm{MPa}$.

The length of the ferrite-filled line is $800 \mathrm{~mm}$, which is enough to decrease the rise time from $40 \mathrm{nsec}$ down to $2-3 \mathrm{nsec}$. The amplitude of pulses to be sharpened is up to $25 \mathrm{kV}$.

Electrical properties of ferrites lead to the necessity to use ferrite rings with sizes not less than M20×12×6 and additional insulation. The later not only increases electrical strength but also makes it possible to achieve the required impedance and increases mechanical strength of the line, performing the role of a shock absorber for fragile ferrite rings. Low-cost and easy-to-get ferrites include among others MnZn (trade-mark 1000MH) and NiZn (trade-mark 1000HH). Owing to low resistivity, 
ferrites of the MnZn type have large losses because of eddy currents. So, preference was given to NiZn ferrites of the type.

Figure 2 presents the experimental dependence of rise time $(\mathrm{t})$ of pulse after pass one of the ferrite line on magnetic field value on the line $\left(\mathrm{H}_{\text {ferr }}\right)$. One can see, that sharpening to (2-3) nsec is arrived at the magnetic field $\mathrm{H}_{\text {ferr }}=8 \mathrm{kA} / \mathrm{m}$.

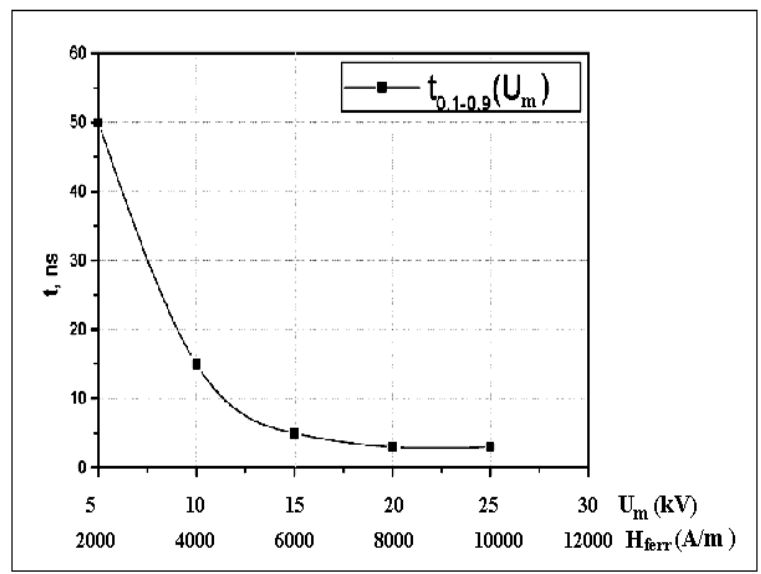

Figure 2. The experimental dependence of rise time (t) of pulse after pass him of ferrite line from size magnetic field on line $\left(\mathrm{H}_{\text {ferr }}\right)$

Figure 3 presents oscillogram of pulse after ferrite line. Amplitude of pulse equal to $24 \mathrm{kV}\left(\mathrm{U}_{\mathrm{m}}=24 \mathrm{kV}\right)$. Rise time equal to $3 \mathrm{nsec}$ at a level of (0.1-0.9) from the amplitude.

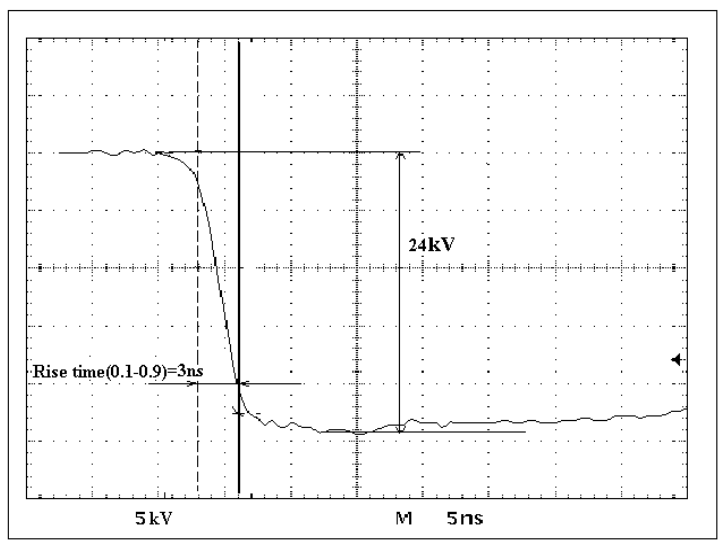

Figure 3. Oscillogram of pulse after ferrite line, at terminal load equal to $50 \mathrm{ohm}$.
If an additional polyethylene insulation us used, which provides the required electrical strength, then the impedance of the line in the saturation mode becomes close to $50 \mathrm{Ohm}$. That is convenient at transmission of pulses by RF cables of the with a $50 \mathrm{Ohm}$ impedance. It is advisable to avoid mechanical treatment of ferrites at manufacture of ferrite lines. Such a treatment worsens their properties. Annealing by a special thermal cycle is required.

\section{THYRATRON GENERATOR ON THE DOUBLE PFN WITH SUBSEQUENT SHARPENING OF RISE TIME WITH THE HELP OF FERRITE LINES}

This generator is planned to be installed on the VEPP2000 complex at Budker Institute of Nuclear Physics SB RAS instead of the generator on the 3-electrode spark-gap with sequential control of the same type as in [5].

Figure 4 presents an elementary circuit of the generator. Its it main elements are:

- LOW VOLTAGE PS - a stable (up to $2 \cdot 10^{-3}$ ) pulsed power supply $(0-800 \mathrm{~V})$,

- TR1- a high-voltage step-up pulse transformer,

- $\quad \mathrm{R} 2-\mathrm{a}$ resistor assigning current of charge of the forming line,

- TL1-TL4 - transfer lines (50 Ohm cables),

- FERRITE LINE - co-axial ferrite lines filled with $\mathrm{M} 20 \times 12 \times 61000 \mathrm{HH} \mathrm{mm}$ rings $800 \mathrm{~mm}$ long

- R_LOADE -. terminal matching loads with measuring divisors to control amplitudes of pulses passing through the ferrite lines.

- $\quad \mathrm{PFN}-\mathrm{a}$ double pulse forming network by lumped parameters.

The double forming line consists of two stages that are charged in parallel and discharged in series. Each stage consists of two sections connected in parallel. Each section consists of 8 cells. Each cell is made by two connected-in-series capacitors of the KVI-3 type with a $470 \mathrm{pF}$ capacitance and a $74 \mathrm{nH}$ inductance made by a coil consisting of 4 turns. The output resistance of the generator equals $25 \mathrm{Ohms}$. The thyratron filament is fed by a stabilized power supply PS for $6.3 \mathrm{~V}$, which provides a small jitter of output pulses. Safe servicing is provided by the breaker K1. It breaks the supplying circuit and switches off high voltage at opening of the doors of the metal cabinet where the generator locates. On the ferrite lines the pulse edge is shortened down to 2-3 nsec and arrives through the kicker to the matching active load with the measuring divisor at the end. 


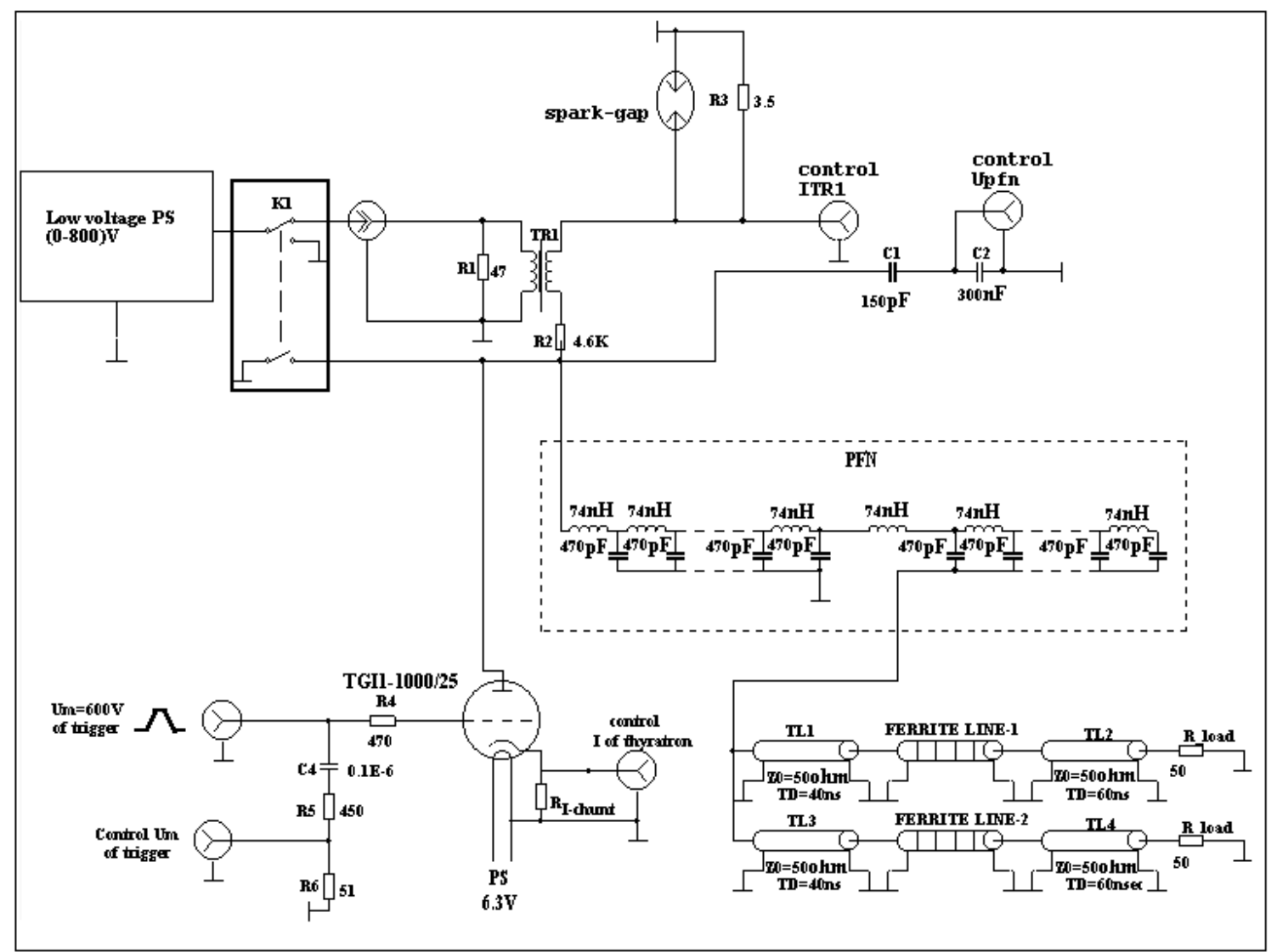

Figure 4. Elementary circuit of the generator with lumped parameters with sharpening on ferrite lines.

\section{REFERENCES}

[1] I.G.Kataev, "Shock electromagnetic waves", 1963.

[2] I.G.Kataev, N.F.Lipatov et al "Generator of highpower nanosecond pulses on non-linear transmission lines with ferrite", Instruments and technology of experiment, N5, 1971.

[3] G.I. Goldenberg, I.G.Kataev, "Lines with ferrite to achieve sharp overfalls of nanosecond power", Instruments and technology of experimet, N 3, 1968.

[4] A.N.Meshkov, «Generator of high-voltage nanosecond pulses", Instruments and technology of experiment, N5, 1965.

[5] A.V.Kiselev, "Dissertation", Novosibirsk, 1965. 